\title{
PREFACE: DROPS, BUBBLES, AND THIN FILMS, SPECIAL ISSUE HONORING PROFESSOR OLEG KABOV
}

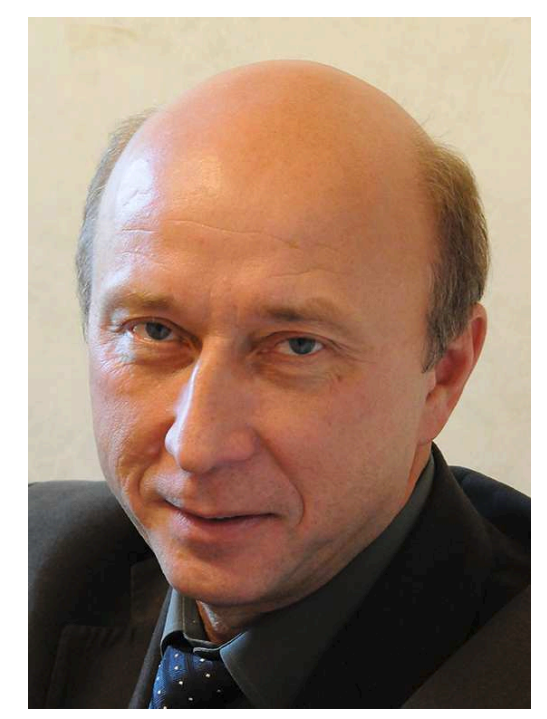

On January 10th, 2016, Professor Oleg Kabov, a world renowned expert in the field of interfacial heat and mass transfer and the founding Editor-in-Chief of the journal Interfacial Phenomena and Heat Transfer (IPHT), celebrated his 60th birthday. To mark the occasion, several of his colleagues conceived the idea of a special issue to celebrate his achievements and to provide an overview of some recent developments in the research areas pioneered and/or enhanced by Professor Kabov. We review his contributions to these areas here while also providing some biographical information.

Oleg Kabov graduated from Tomsk Polytechnic Institute (now National Tomsk Polytechnic Research University) in 1978, and in the same year he moved to Novosibirsk to join the laboratory of Professor S.S. Kutateladze at the Institute of Thermophysics. For many decades, this institute has been one of the leading heat and mass transfer research centers in the world, in part due to the pioneering contributions of Kutateladze and his collaborators toward the understanding of physical mechanisms of boiling and condensation. Other important research areas developed at the Institute of Thermophysics include studies of waves on liquid films, vortex flows, heat and mass transfer in disperse systems, phase transformation at cryogenic temperatures, detonation, rarified gas dynamics, and synthesis of advanced materials. Professor Kabov defended his $\mathrm{PhD}$ thesis at the Institute of Thermophysics in 1987 under the direction of Professor I.I. Gogonin by working on problems of film condensation on arrays of finned tubes. The photograph in Fig. 1 (left) goes back to the early days at the Kutateladze laboratory. The colleagues at the Institute of Thermophysics quickly recognized Oleg's scientific potential. In 1987, at the age of just 31, he became the head of a new laboratory for heat transfer enhancement, see Fig. 1 (right). Professor Vladimir E. Nakoryakov, an outstanding scientist who was the Director of the Institute of Thermophysics between 1986 and 1997, proposed and strongly supported the establishment of this laboratory.

In search of novel research directions for his laboratory, Professor Kabov turned his attention to studies of gravitydriven liquid films flowing over heated surfaces. This work resulted in a remarkable discovery (Kabov, 1998). While 

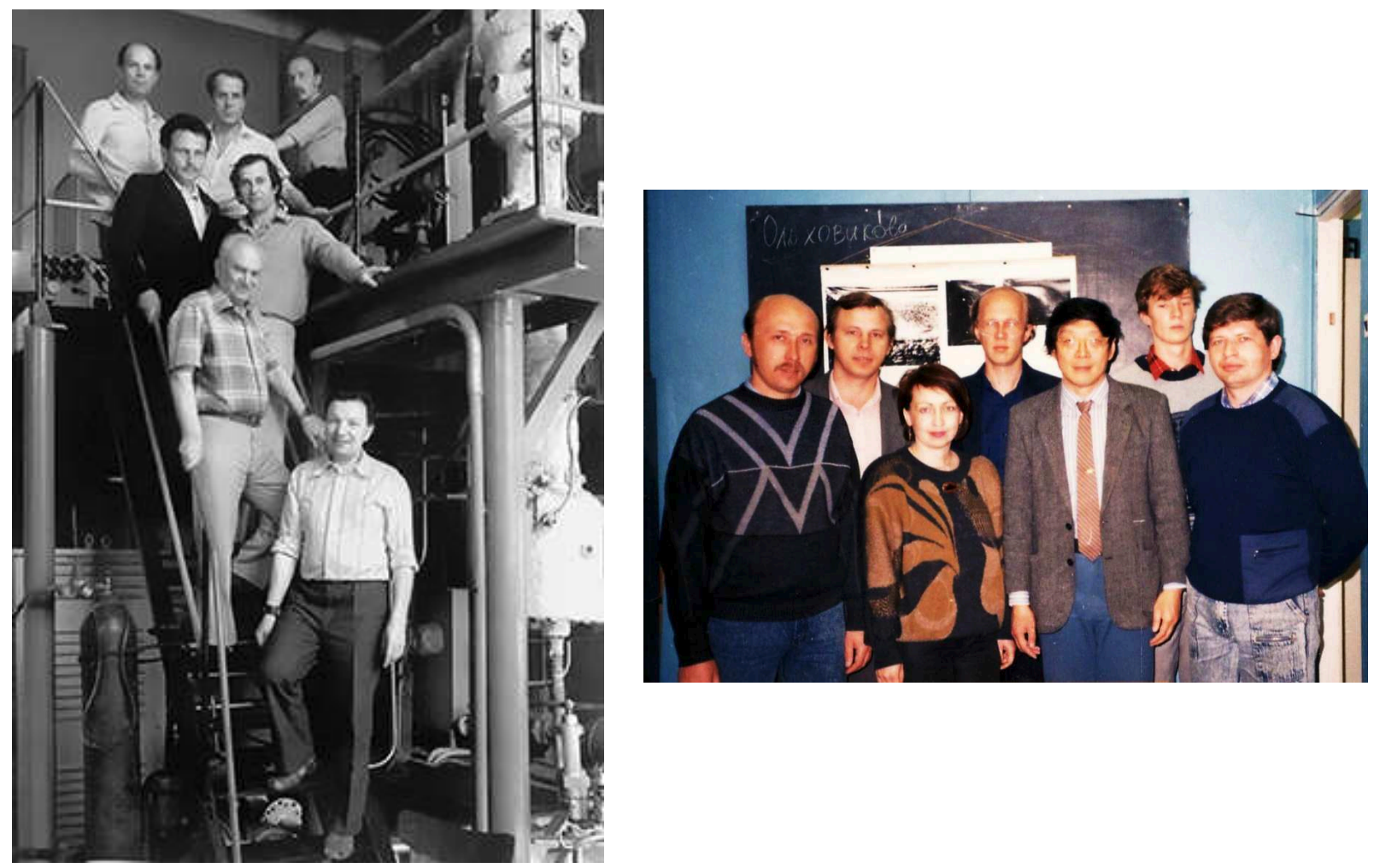

FIG. 1: (Left) Professors I.I. Gogonin (at the bottom of the stairs) and S.S. Kutateladze (next to him) with a group of Kutateladze laboratory members, Oleg Kabov is in the top row on the right; (right) A photograph from the early days of Kabov's laboratory taken during a visit from Professor C.F. Ma (China), third from the right (O.A. Kabov is first from the left and E.A. Chinnov is in the middle)

conducting experiments with films of a water-ethanol mixture flowing down a vertical rectangular heated plate, Oleg made the first reported observations of the regular interfacial structures shown in Fig. 2. These structures can be described as arrays of rivulets, separated by thin film regions and connected the top via horseshoe-shaped elements. For rectangular heaters used in experiments, the structures are bounded by edge waves at the two ends of the heater. The three-dimensional structures appear when the heat flux is above a certain critical value, which was found to depend on the flow Reynolds number in a nearly linear fashion. Based on accurate optical recordings of the deformed films, the distance between rivulets was found to increase with the heat flux. Since heating clearly plays a role in the formation of arrays of rivulets, Professor Kabov and his colleagues went on to conduct elaborate infrared studies of these structures and uncovered the presence of significant temperature gradients. These studies were conducted together with Igor V. Marchuk, one of the first members of the newly established laboratory. In 2000, Marchuk defended his PhD dissertation under the direction of Professor Kabov. To the present day, Professor Marchuk continues to work in the laboratory while also serving as Dean of the Department of Mathematics and Mechanics at Novosibirsk State University.

Further detailed studies of these regular structures were conducted using the Schlieren method (Kabov et al., 2001). A typical result is shown in Fig. 3 (top). An interesting feature clearly seen in Fig. 3 is a small rivulet formed as a result of a secondary instability. Professor Kabov also collaborated with Professor A. Frank from Krasnoyarsk on a seminal paper providing a detailed comparison between the regular structures seen in the experiments and numerical simulations described in that study. A typical result from these simulations is shown in Fig. 3 (bottom). Note that not only are the overall shapes of the structures reproduced in these numerical simulations but also the shapes of 

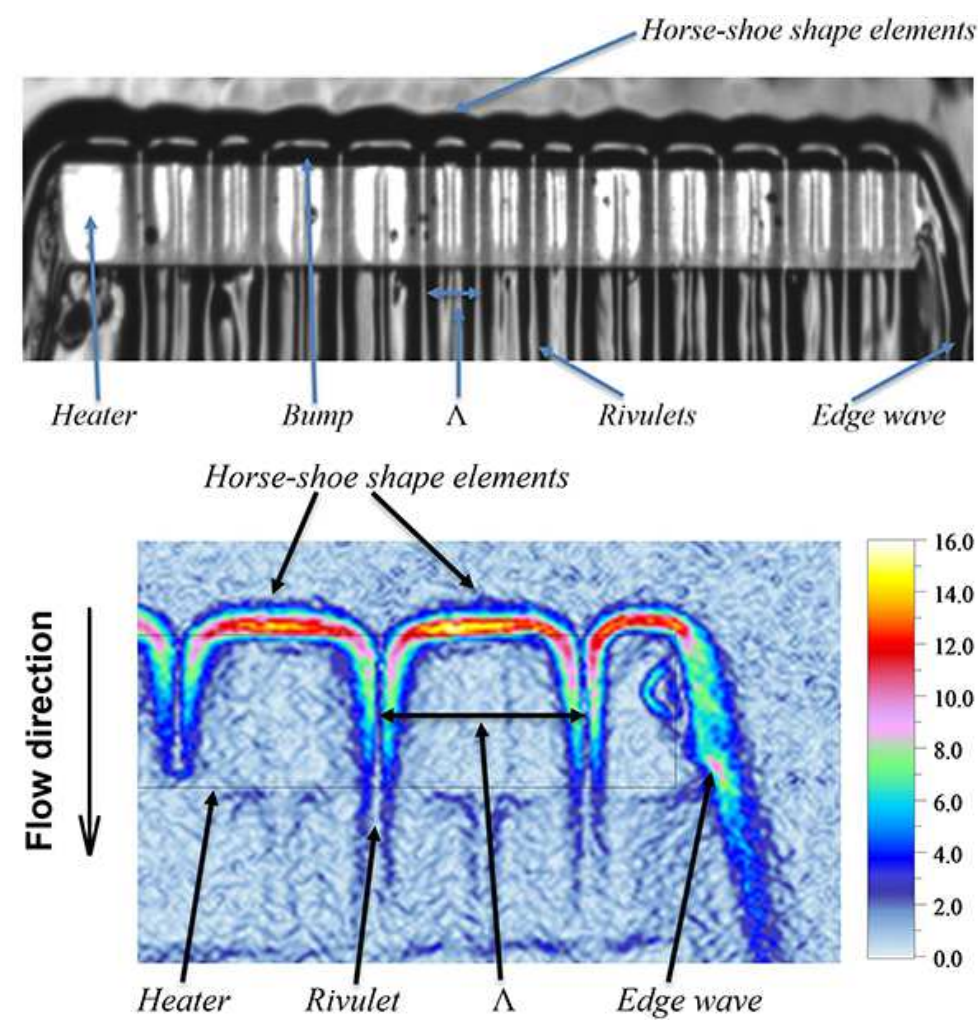

FIG. 2: (Top) Regular interfacial structures discovered by O.A. Kabov observed via optical observation techniques [film of $10 \%$ ethyl alcohol in water on a $6.75 \times 109 \mathrm{~mm}^{2}$ heater; $\mathrm{Re}=1, q=2.37 \mathrm{~W} / \mathrm{cm}^{2}$; image was obtained using the experimental setup from Kabov et al. (2001)] and (bottom) infrared observation techniques [temperature gradient $(\mathrm{K} / \mathrm{mm})$ on the film surface; using the setup discussed in Kabov (2010)]

the secondary rivulets seen experimentally. The significance of the temperature gradients and resulting Marangoni stresses, as determined by the Marangoni number (Ma), in the process of formation of regular structures is clearly illustrated. The simulations indicate significant growth of the width of the structure with increasing Ma values.

Detailed experimental studies of regular interfacial structures formed at different heater sizes were conducted in collaboration with Professor E.A. Chinnov and led to the determination of the formation conditions and geometric characteristics of different structures (Chinnov and Kabov, 2003). Professor Chinnov has been working in the laboratory for many years and has also produced a number of important results on flow regimes for multiphase flows in channels (Chinnov and Kabov, 2006; Chinnov et al., 2016); these studies resulted in clarification of the role of the channel height and width for two-phase flows in horizontal micro-gaps, as illustrated in Fig. 4.

Studies of thin films flowing down heated vertical and inclined solid surfaces indicate the conditions under which rupture of the film can occur, resulting in the formation of a dry patch. Typically, such dry patches originate at the edge of a heating element and rapidly expand. While many previous researchers simply tried to focus their research on experimental regimes in which rupture does not occur, Professor Kabov was one of the first scientists to realize that identifying the conditions for rupture and the dynamics of liquid films with dry patches are of tremendous importance for various heat transfer applications, in which formation of a dry patch could result in a rapid local increase in the surface temperature. Careful experimental studies of rupture started in Kabov's group in 1994. The effects of the linear size of the heater and the surface properties were investigated (Kabov, 2000), paving the way for subsequent studies, including a series of works in collaboration with Dr. Dmitry Zaitsev. Many novel results on rupture were obtained using a double fiber-optical probe, a method that depends on detection of a change in intensity of reflected light as 


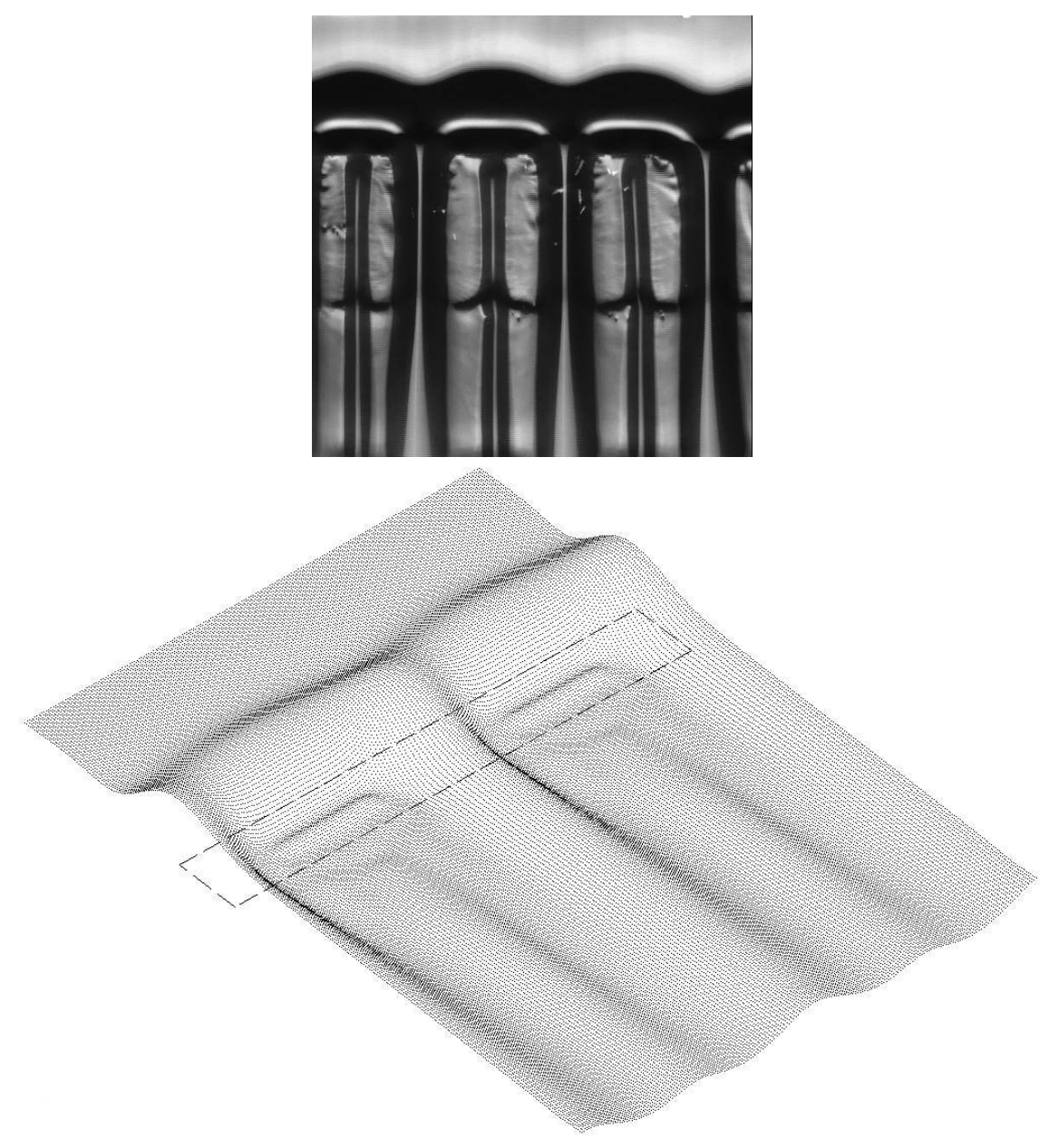

FIG. 3: Schlieren images: (top) $6.7 \times 68 \mathrm{~mm}^{2}$ heater, $25 \%$ ethyl alcohol, $\mathrm{Re}=1, q=3.9 \mathrm{~W} / \mathrm{cm}^{2}$; (bottom) numerical simulations of regular structures formed in gravity-driven films on rectangular heaters (reprinted with permission from AIP, Frank and Kabov, 2006)

a function of the distance between a probe and reflecting surface (Zaitsev et al., 2003). Experiments with horizontal liquid layers on locally heated substrates show the formation of a flat, ultra-thin, residual layer prior to the rupture, as shown in Fig. 5 (left); this layer can persist for several seconds, e.g., in the case of ethanol.

Professor Kabov's interest in using liquid films for cooling applications led to several pioneering experimental and numerical studies of shear-driven films, i.e., films driven by the effects of shear stress from co-current gas flow. The advantage of this configuration for applications, when compared to gravity-driven films, is that it can be operational at much smaller length scales, making it potentially suitable for microscale cooling devices. Also, shear-driven films are found to be less likely to rupture than gravity-driven films under the same heating conditions, although the breakdown is still possible, see Fig. 5 (right). Experimental studies were conducted as presented in a series of papers mostly in collaboration with V. Cheverda, Y. Lyulin, and D. Zaitsev, while theoretical and numerical work was done by E. Gatapova (Gatapova and Kabov, 2008) and Yu. Kabova (Kabova et al., 2009). In particular, the pioneering study of Gatapova and Kabov (2008) was the first to incorporate the effects of evaporation due to the presence of localized heating into a mathematical model of shear-driven film. More recent elaborate numerical simulations are based on fully three-dimensional unsteady two-sided models of the coupled motion of the liquid film and the gas above it, 


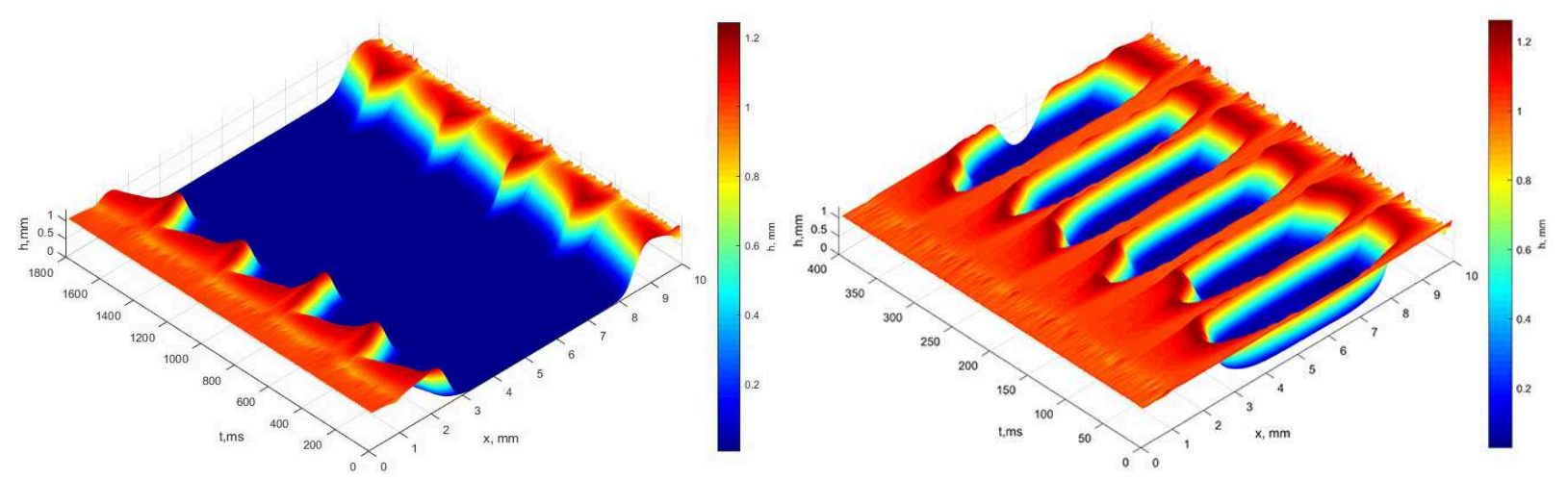

FIG. 4: Two-phase air-water flow in horizontal mini- and microchannels of rectangular cross sections: instability of the stratified flow (left) and bubble flow regime (right); images were obtained by the fluorescent method using the experimental setup adapted from Chinnov et al. (2016)

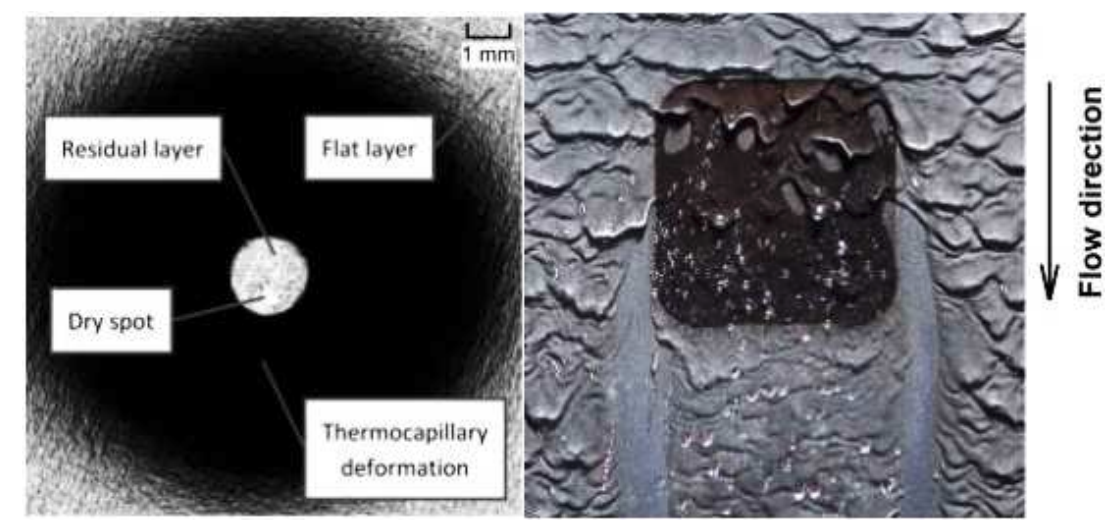

FIG. 5: (Left) Residual layer and its rupture during localized heating of a $700 \mu \mathrm{m}$ layer of ethanol by a $1.6 \mathrm{~mm}-$ diameter heater $\left(q=95 \mathrm{~W} / \mathrm{cm}^{2}\right)$, the results were obtained using the experimental setup adapted from Lyulin et al. (2015); (right) destruction of a shear-driven water film in a horizontal microchannel with a $1 \mathrm{~cm} \times 1 \mathrm{~cm}$ heater [channel height of $1.2 \mathrm{~mm} ; q=210 \mathrm{~W} / \mathrm{cm}^{2}$; Re $=30$ and 2550 for liquid and gas, respectively; adapted from Kabov et al. (2014b)]

resulting in pictures such as the one in Fig. 6. Experimental studies of shear-driven flows in narrow gap channels resulted in detailed maps of flow regimes, providing valuable guidance for practical applications (Kabov et al., 2007, 2011). Using the Schlieren method, it was found that there are two types of waves in non-isothermal shear-driven films, longitudinal and transversal, as is clearly illustrated in Fig. 7. The physical mechanisms of wave formation are different: thermocapillary and hydrodynamic. For the thermocapillary driven wave formation, shown in Fig. 7 (left), the wavelength is shown to depend on the temperature, the values of the Reynolds number for both liquid and gas, and the gravitational acceleration.

In 2001, Professor Kabov was invited to start a research group at the Microgravity Research Center of the Free University of Brussels, Belgium. For about a decade, Professor Kabov divided his time between Russia and Belgium. Many important experiments were conducted in the international and interdisciplinary laboratory headed by Professor Kabov. Novel research directions included studies of sessile droplets, convective flows in evaporating liquid layers, and condensation in channels. Sessile droplets (Gatapova et al., 2014) are considered to be sufficiently large for the effect of gravity on the shape to be important; these droplets were studied for the first time by using a model that incorporated heat transfer in the gas, rather than dealing only with simple diffusion. Studies on condensation included 


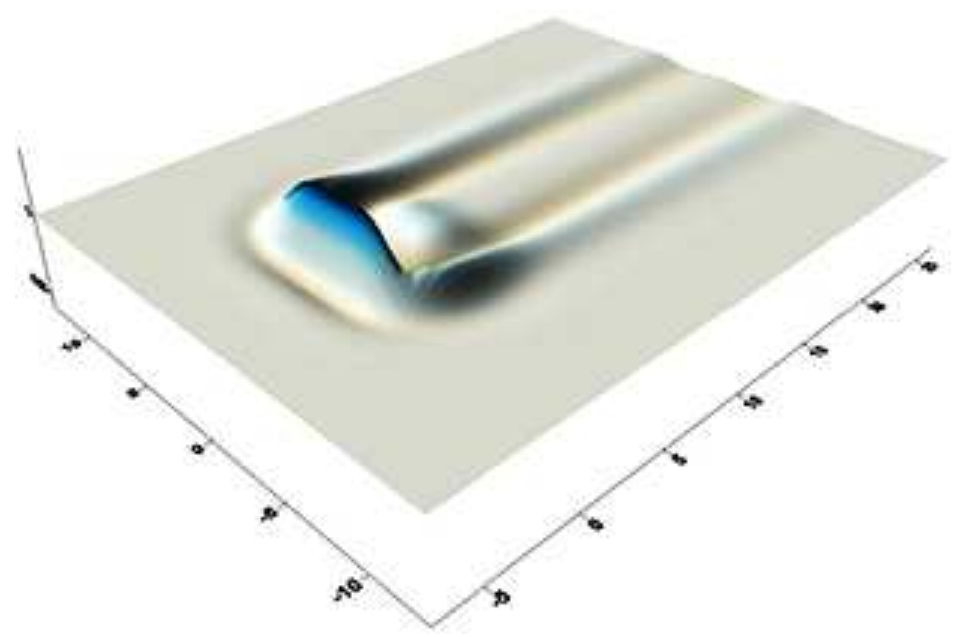

FIG. 6: Numerical simulations of a shear-driven film on a heated substrate [horizontal channel height, $250 \mu \mathrm{m}$; heater size, $2 \times 10 \mathrm{~mm}^{2} ; \mathrm{Re}=3$ and 15 for liquid (water) and gas (nitrogen), respectively]; the initial mass concentration of vapor in the gas was $0.016931 \mathrm{~kg} / \mathrm{m}^{3}$, the initial fluid temperature and temperature at the heater surface were $20^{\circ} \mathrm{C}$ and $25^{\circ} \mathrm{C}$, respectively [the results were obtained using the technique adapted from that developed by Kabova et al. (2014)]
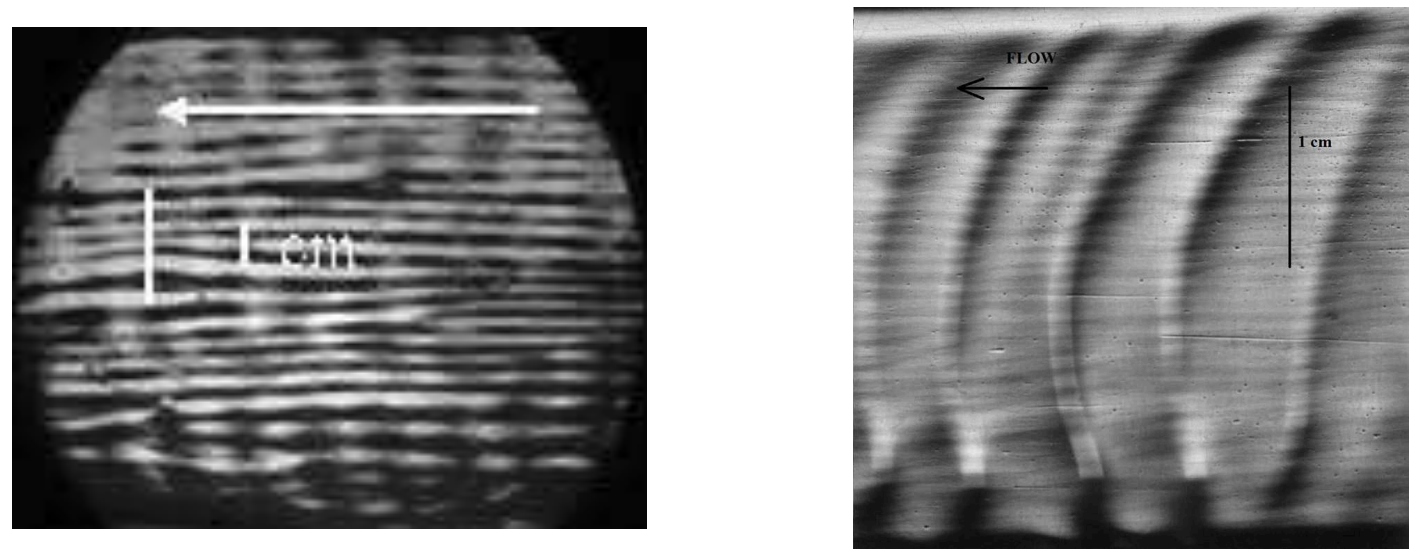

FIG. 7: Schlieren images of thermocapillary structures (left) and hydrodynamic two-dimensional and threedimensional waves (right) for two-phase flow of FC-72 and nitrogen [the results were obtained using the experimental setup adapted from Kabov et al. (2011)]

new results on pure vapor condensation inside inclined circular tubes (Lyulin et al., 2011). Group members took advantage of the remarkable opportunity to conduct experiments in microgravity during parabolic flights on board the European Space Agency (ESA) test aircraft (see Fig. 8). Studies of shear-driven films, rivulets, sessile drops, condensation, and boiling were conducted on these flights (for examples of this research, see Kawanami et al., 2009; Kabov and Zaitsev, 2013).

Since 2012, Professor Kabov has devoted all of his time toward developing novel state-of-the-art experimental facilities at the Laboratory of Enhancement of Heat Transfer in Novosibirsk. Many young people have joined the laboratory, which is supported by research grants from the Russian Science Foundation, Russian Foundation for Basic Research, and Russian Ministry of Science and Education. The tradition of international cooperation has continued, 


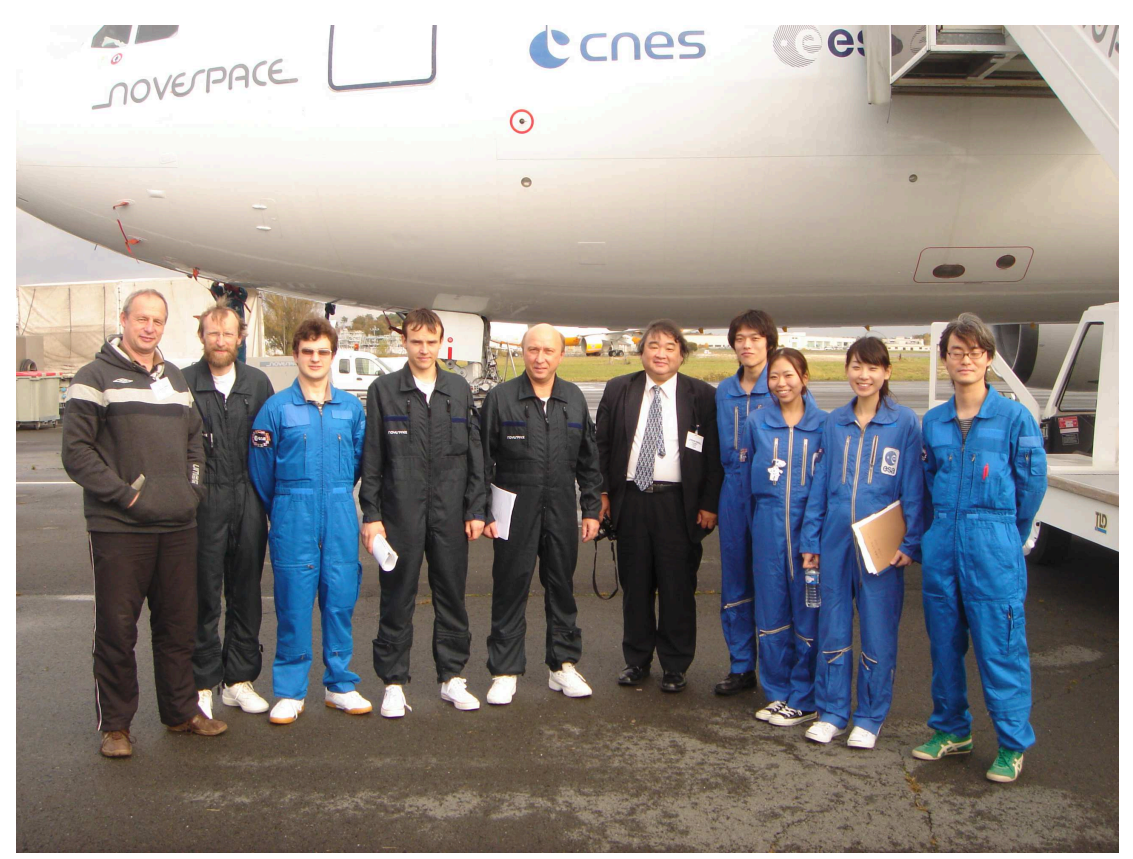

FIG. 8: Professors O.A. Kabov and H. Ohta (Japan) with their group members in front of the aircraft used to conduct their parabolic flight experiments

with a steady stream of both short- and long-term visitors, including Professors B.-F. Bai (China), A. Bar-Cohen (United States), S.H. Davis (United States), P. DiMarco (Italy), H. Guo (China), S. Khandekar (India), J.C. Legros (Belgium), H. Ohta (Japan), and J.-F. Zhao (China). Not only have the traditional areas of strength continued to be developed, but also new topics and classes of problems have attracted attention. For example, combined theoretical and experimental studies of the interface between liquid and vapor, with particular focus on the possibility of a temperature jump across the interface, were conducted in collaboration with researchers from France and Brazil (Gatapova et al., 2015). These resulted in the first detection of a temperature jump under normal atmospheric conditions using microthermocouples (2-3 $\mu \mathrm{m}$ in size), as well as a comparison with theoretical models. Another example of a promising new research direction for the laboratory is the study of levitating droplets over both liquid and solid surfaces. Such droplets are known to form regular two-dimensional arrays over an evaporating liquid layer. These droplets became the subject of several investigations, resulting in the elucidation of the nature of the levitation (Kabov et al., 2014a; Zaitsev et al., 2017). Furthermore, these droplets were used as tracer particles in a novel approach for studies of local gas flow near contact lines, which are boundaries of a dry patch; remarkably, the droplets also were found to levitate when they cross the contact line region to the dry area (Kabov et al., 2016). The actual process of droplet fly-over, as illustrated in the photograph in Fig. 9, can be used to record information about the position (and thus velocity and acceleration) of droplets as functions of time. These data were then used to obtain information on the force from the gas flow acting on the droplet, eventually leading to the value of the local gas flow velocity at the location of the droplet. In addition to this practical aspect, there are important fundamental scientific questions related to the nature of self-organization and levitation of droplets over both liquid surfaces and dry substrates, e.g., as seen over the surface of the dry patch in Fig. 9. The process of levitation over the dry heated surface was studied experimentally and explained theoretically by Zaitsev et al. (2017) in terms of the effect of the Stefan flow generated around an evaporating droplet and reflected off the substrate. Other recent studies in Kabov's group have included experiments on droplet impact onto heated substrates and motion of evaporating liquid droplets under the action of gas flow and heat transfer near the liquid-gas-solid contact line (Karchevsky et al., 2016).

While we have mostly focused on the scientific results of Professor Kabov and his collaborators here, a few words about his outstanding record of service to the international scientific community are in order. Professor Kabov started 


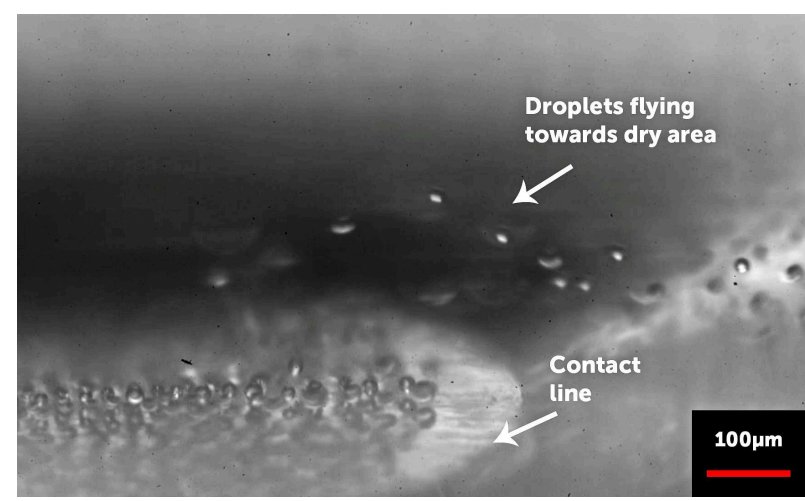

FIG. 9: Frame from a high-speed video recording showing levitating microscale droplets flying over the contact line for the experimental setup adapted from Kabov et al. (2016)

a remarkably successful series of international meetings on two-phase flows for ground and space applications, supported by the ESA. Now in its 12th year, the conference became an important event that has brought together leaders in space research and representatives of funding agencies from Europe, Russia, China, Japan, and the United States; many future space experiments were conceived and discussed at these meetings. The 12th meeting in the series was organized by Professor Kabov and his laboratory in Novosibirsk. More recently, Professor Kabov also initiated a more informal brain-storming-type annual meeting called "Interfacial Phenomena and Heat Transfer." A noteworthy feature of these meetings is the so-called mini-seminar, in which all keynote speakers are invited to participate in a panel discussion of the most challenging problems in the field. These discussions have been characterized by a remarkable degree of openness and enthusiasm. Most importantly, they bring together scientists from different research areas, with the same interdisciplinary spirit as is demonstrated in the IPHT journal, which Oleg Kabov founded. He felt that it was essential to have a forum for publication of results at the intersection of fluid mechanics and heat transfer. Papers from leading research groups in several countries have appeared in the journal over the past few years. The present special issue of IPHT contains contributions from Oleg Kabov's colleagues and friends from several countries and covers a wide range of topics related to his research interests.

\section{REFERENCES}

Chinnov, E.A. and Kabov, O.A., Jet formation in gravitational flow of a heated wavy liquid film, J. Appl. Mech. Tech. Phys., vol. 44, pp. 708-715, 2003.

Chinnov, E.A. and Kabov, O.A., Two-phase flows in pipes and capillary channels, High Temp., vol. 44, pp. 773-791, 2006.

Chinnov, E.A., Ron'shin, F.V., and Kabov, O.A., Two-phase flow patterns in short horizontal rectangular microchannels, Int. J. Multiphase Flow, vol. 80, pp. 57-68, 2016.

Frank, A.M. and Kabov, O.A., Thermocapillary structure formation in a falling film: Experiment and calculations, Phys. Fluids, vol. 18, pp. 032107-1-032107-10, 2006.

Gatapova, E.Ya., Graur, I.A., Sharipov, F., and Kabov, O.A., The temperature and pressure jumps at the vapor-liquid interface: Application to a two-phase cooling system, Int. J. Heat Mass Trans., vol. 83, pp. 235-243, 2015.

Gatapova, E.Ya. and Kabov, O.A., Shear-driven flows of locally heated liquid films, Int. J. Heat Mass Trans., vol. 51, nos. 19-20, pp. 4797-4810, 2008.

Gatapova, E.Ya., Semenov, A.A., Zaitsev, D.V., and Kabov, O.A., Evaporation of a sessile water drop on a heated surface with controlled wettability, Colloids Surf. A, vol. 441, pp. 776-785, 2014.

Kabov, O.A., Formation of regular structures in a falling liquid film upon local heating, Thermophys. Aeromech., vol. 5, no. 1, pp. 547-551, 1998.

Kabov, O.A., Breakdown of a liquid film flowing over the surface with a local heat source, Thermophys. Aeromech., vol. 7, no. 4, pp. 513-520, 2000. 
Kabov, O.A., Interfacial thermal fluid phenomena in thin liquid films, Int. J. Emerging Multidisciplinary Fluid Sci., vol. 2, nos. 2-3, pp. 87-121, 2010.

Kabov, O.A., Fedorets, A.A., and Marchuk, I.V., Heat transfer and interaction of suspended droplets and locally heated liquid layer, in Proc. of 15th Int. Heat Trans. Conf., pp. 2375-2386, 2014a.

Kabov, O.A., Legros, J.C., Marchuk, I.V., and Scheid, B., Deformation of free surface in a moving locally-heated thin liquid layer, Fluid Dyn., vol. 36, no. 3, pp. 521-528, 2001.

Kabov, O.A., Lyulin, Yu.V., Marchuk, I.V., and Zaitsev, D.V., Locally heated shear-driven liquid films in microchannels and minichannels, Int. J. Heat Fluid Flow, vol. 28, pp. 103-112, 2007.

Kabov, O.A. and Zaitsev, D.V., The effect of wetting hysteresis on drop spreading under gravity, Dokl. Phys., vol. 58, no 7, pp. 292-295, 2013.

Kabov, O.A., Zaitsev, D.V., Cheverda, V.V., and Bar-Cohen, A., Evaporation and flow dynamics of thin, shear-driven liquid films, Exp. Therm. Fluid Sci., vol. 35, no. 5, pp. 825-831, 2011.

Kabov, O.A., Zaitsev, D.V., Kabova, Yu.O., and Cheverda, V.V., Evaporation, dynamics and crisis phenomena in thin liquid films sheared by gas in a narrow channel, Proc. of 15th Int. Heat Trans. Conf., pp. 3347-3361, 2014b.

Kabov, O.A., Zaitsev, D.V., Kirichenko, D.P., and Ajaev, V.S., Investigation of moist air flow near contact line using microdroplets as tracers, Interfacial Phenom. Heat Transfer, vol. 4, nos. 2-3, pp. 207-216, 2016.

Kabova, Yu.O., Kuznetsov, V.V., and Kabov, O.A., The effect of gravity and shear stress on a liquid film driven in a horizontal minichannel at local heating, Microgravity Sci. Technol., vol. 21, no. 1, pp. S145-S152, 2009.

Kabova, Yu.O., Kuznetsov, V.V., Kabov, O.A., Gambaryan-Roisman, T., and Stephan, P., Evaporation of a thin viscous liquid film sheared by gas in a minichannel, Int. J. Heat Mass Trans., vol. 68, pp. 527-541, 2014.

Karchevsky, A.L., Marchuk, I.V., and Kabov, O.A., Calculation of the heat flux near the liquid-gas-solid contact line, Appl. Math. Modell., vol. 40, pp. 1029-1037, 2016.

Kawanami, O., Ohta, H., Kabov, O., Sakata, Y., Kotani, Y., Asada, Y., Nagayasu, T., Shinmoto, Y., Chikov, S., Queeckers, P., and Straub, J., Heat transfer and bubble behaviors in microgravity pool boiling in ESA parabolic flight experiment, Microgravity Sci. Technol., vol. 21, no. 1, pp. S3-S8, 2009.

Lyulin, Yu.V., Marchuk, I.V., Chikov, S.B., and Kabov, O.A., Experimental study of laminar convective condensation of pure vapor inside an inclined circular tube, Microgravity Sci. Technol., vol. 23, no. 4, pp. 439-445, 2011.

Lyulin, Yu.V., Spesivtsev, S.E., Marchuk, I.V., and Kabov, O.A., Investigation of disruption dynamics of horizontal liquid layer with spot heating from the substate side, Tech. Phys. Lett., vol. 41, pp. 1034-1037, 2015.

Zaitsev, D.V., Kabov, O.A., and Evseev, A.R., Measurement of locally heated liquid film thickness by a double-fiber optical probe, Exp. Fluids, vol. 34, pp. 748-754, 2003.

Zaitsev, D.V., Kirichenko, D.P., Ajaev, V.S., and Kabov, O.A., Levitation and self-organization of liquid microdroplets over dry heated substrates, Phys. Rev. Lett., vol. 119, 2017.

On behalf of the Editorial Board:

V.S. Ajaev

Southern Methodist University, USA

S.V. Alekseenko

Institute of Thermophysics, Russia

A. Bar-Cohen

University of Maryland, USA

L.-A. Davalos-Orozco

UNAM, Mexico

Volume 4, Issue 4, 2016 
P. DiMarco

University of Pisa, Italy

H. Guo

Beijing University of Technology, China

D.M. Markovich

Institute of Thermophysics, Russia

H. Ohta

Kyushu University, Japan

L. Tadrist

Aix-Marseille University, France

J.-F. Zhao

Institute of Mechanics, China 